\title{
Design of Dynamometer for Engine Testing
}

\author{
Prof. Mahesh Kanojiya ${ }^{1}$, Samir Chunne ${ }^{2}$, Amit Sahani ${ }^{3}$, Paras Ghate ${ }^{4}$, Girish Walki ${ }^{5}$, \\ Vipul Dalvi ${ }^{6}$, Kunal Katkar ${ }^{7}$, Sumit Sonkusle ${ }^{8}$, Shubham Chaware ${ }^{9}$ \\ ${ }^{1}$ Assistant Professor, ${ }^{23456789}$ UG Students, Department of Mechanical Engineering, NIT, Nagpur, India
}

Received on: 18 May, 2021, Revised on: 21 June, 2021, Published on: 23 June, 2021

\begin{abstract}
Strict emission regulations for vehicles and advances in automotive technology, dictate the thorough testing of engines, fuels and emissions. In past work at $P M U$, a port fuel injection engine was assembled and tested on biofuel blends. However, the engine was operating on free load. To simulate the effect of load torque on the engine, in this project, we design a break dynamometer. The dynamometer consists of a flange to mount on the PMU engine, a break array, a strain gage, and protective covers. The students will have to perform extensive stresses calculations and FEA analysis prior to manufacturing.
\end{abstract}

Keywords- Dynamometer; Engine; Power; Mechanical Gauges; PMU Engine

\section{I- INTRODUCTION}

$\mathbf{T}$ his project is intended to design and manufacture a simple rotor test rig, where rotor faults can be inserted and tested. The test rig is to be fitted with vibration sensors to enable collecting data and use it to monitor the health of machines. The project is very important to industry as through understanding the characteristics of failure, time and money will be saved. This is also very important from the safety prospective as this will lead to a safe operating environment for rotary machines. This project is intended design a break dynamometer. The dynamometer consists of a flange to mount on the PMU engine, a break array, a strain gage, and protective covers. The students will have to perform extensive stresses calculations and FEA analysis prior to manufacturing.

\subsection{Project Specifications}

The dynamometer can be used on any type of engine with only adjustments required for the type of engine it's going to be used on. The parts for dynamometer can be seen in table 1.1 below.

Table 1- Name of Parts

\begin{tabular}{|c|c|}
\hline Shaft & Disk \\
\hline Brakes & Shaft \\
\hline Bearings & Bearings \\
\hline Tachometer & Trolley \\
\hline Optical Thermommeter & Safety Cover \\
\hline Force Gauge & Caliper Holder \\
\hline
\end{tabular}

To measure brake power, the angular speed and torque has to be measured. Therefore, the rotor is driven by the engine under test by Hydraulic, mechanical or electromagnetic means.

\subsection{Applications \& Objectives} Applications

The dynamometer can be used for many different applications. It can fit many criteria to help people in certain areas. The following are the applications for dynamometer:

- Test the IC engine

- Measuring torque of any rotary member, just by coupling with the shaft of dynamometer

- Can be used as a speed controller or load controller. 


\section{International Journal of Innovations in Engineering and Science, www.ijies.net}

\section{Objectives}

1. Design and build a dynamometer (shaft, breaks, safety cover, bearings and housing).

2. Develop the instrumentation of the dynamometer (force gage, rotational speed meter and optical temperature).

3. Test the dynamometer.

4. Measure breaks engine power output.

\section{II - LITERATURE REVIEW}

Rolling element bearings are core components of our revolutionary life and developments. They exist in almost all rotary machines, supporting their dynamic forces and facilitating their rotation. The failure of a rolling element bearing may have a catastrophic consequence on the machine if it went undetected and without follow-up. We attempt to monitor these vital components through observing their temperature, noise, vibrations, oil wear debris etc. Among all these monitored parameters, vibration signals have proven to be of great assistance for maintenance personnel, not only in detecting the presence of a fault but also in locating its source. Most recently, information from vibration signals has been used to provide analysts with an idea about the size of the fault and consequently enable prediction of the useful remaining life of the bearing (prognostics). However, vibrations picked up by accelerometers have to go through a number of rigorous processing steps to enable extraction of the fault symptoms and identification and quantification of fault size.

\section{Mechanical force gauge}

Mechanical force gauge is an instrument that used to measure both compression and tension force for both ways pulling or pushing. Depends of the vendor product, its considered as a highly accurate tool to measure the mentioned forces above also it measure Peak force by using the peak indicator needle and depends on the weight of the attached item.

\section{Spring gauge :}

It's a type of weighing scale which is a device to measure mass and this spring made of a fixe spring at on side with hook to attach an object at the other, this spring works by Hooke's Law ( $\mathrm{F}=\mathrm{KX}$ ) where $\mathrm{K}$ represent constant factor characteristic of the spring and $\mathrm{X}$ represent the distance. On the other hand, spring force gauge can only measure weight and can't measure mass.
Moreover, A spring gauge can only scan properly in a very frame of reference wherever the acceleration within the spring axis is constant, for example on earth, wherever the acceleration is as a result of gravity).Also, spring gauge have different sizes, in general small size that measure newton will have a less fixed grip on the spring than the larger size that can be measure thousands and tens of newton's or even more than that and that depends on the scale that you use. In fact, the largest spring gauges measurement can be ranged from 5000 to 8000 newton.

\section{Deformation gauge:}

Knows also as strain gauge, it convert force weight, tension and pressure into in to electrical resistance that can be measure. When you applied external forces to a fixed object strain and stress are the result. A typical gauge arranges an extended, skinny conductive strip during a zigzag pattern of parallel lines. This doesn't increase the sensitivity, since the percentage modification in resistance for a given strain for the complete zigzag is that the same as for any single trace. However, one linear trace would need to be very thin and therefore at risk of over warming (which would each modification its resistance and cause it to expand), or would got to be operated at a far lower voltage, creating it tougher to measure resistance changes accurately.

\subsection{Our Findings}

After going through all the research papers, we found that there is definitely some problem with everything. Most of those research papers have used chain drive, gear drive or some other mechanism, most of them used belt drive. we are using a different hi mechanism which is a lead screw mechanism this is our finding. This lead mechanism is being used. We don't know if a similar test has happened, we don't need it or we don't need to do it consistently, we'll just use it occasionally.

\section{III- METHODOLOGY AND APPROACH TO DESIGN}

\section{- Geometrical Constraints}

Calculations has been done to design our project are bearing life, volume and mass of the shaft, radial load, and key dimensions.

- Sustainability

Based on design and material property standards, we expect a sustainable system.

- Social and Environmental

Dynamometers are important technology that effect social communication through the 


\section{International Journal of Innovations in Engineering and Science, www.ijies.net}

automobile industry, and environmentally by reducing the consumption of fuel in these types of systems.

\section{- Manufacturing}

Dimension and solid work design will be given to the workshop to execute and manufacture the parts.

- Safety

Our system will be covered by heavy plastic to avoid injuries while running tests.

\section{Engineering Design standards}

Engine testing (Engine power code: J2723-_201509)

Shaft standard (Steel AISI1020)

Bearing Caliber, Caliber stand, Table

\section{IV- THEORY AND THEORETICAL CALCULATIONS}

Where:

$\mathrm{L} \square \square_{0}$ : Bearing life

LR: Desired life, hours

C $\square 0_{0}$ : Catalog rating life

$\mathrm{N}$ : revolution per minute

Fe: equivalent steady radial load

Volume of shaft:

$v=\pi r^{2} L$

$v=\pi(0.025 m)^{2}(1 \mathrm{~m})=1.9625 \times 10^{-3} \mathrm{~m}^{3}$

\section{Mass of Shaft:}

$m=\rho \times v$

$\mathrm{m}=7872=\frac{\mathrm{Kg}}{\mathrm{m}^{3}} \times 1.9625 \times 10^{-3} \mathrm{~m}^{3}=15.45 \mathrm{Kg}$

\section{Radial Load}

$$
\begin{aligned}
& F_{\mathrm{r}}=\frac{T}{r} \\
& F_{\mathrm{r}}=\frac{143 \mathrm{~N} \cdot \mathrm{m}}{0.025 \mathrm{~m}}=5720 \mathrm{~N}
\end{aligned}
$$

(Eq. 1.4)

Steady equivalent radial load $\mathrm{Fe}$

$$
\mathrm{Fe}=\mathrm{X}_{2} \quad \mathrm{VF}_{\mathrm{r}}+\mathrm{Y}_{2} \quad \mathrm{~F}_{\mathrm{a}}
$$

$\frac{f a}{C 0}-\frac{5720}{19.6 \times 10^{3}}=0.29$ which $\mathrm{e}$ is between 0.28 and 0.42
Interpolating for $\mathbf{e}$

$$
\begin{aligned}
& \frac{0.42-0.28}{0.42-0.29}-\frac{0.42-0.38}{0.42-x}=\mathrm{e}=0.384 \\
& \frac{f a}{V * \mathrm{~F}_{\mathrm{r}}}-\frac{5720}{1 * 15.45 \times 10^{3}}=0.37 \text { so } \mathrm{Y}_{2}=1 \\
& \mathrm{Fe}=\mathrm{X}_{2} * \mathrm{~V}^{*} \mathrm{~F}_{\mathrm{r}}+\mathrm{Y}_{2} * \mathrm{~F}_{\mathrm{a}}=0.56(1)\left(15.45 \times 10^{3}\right)+ \\
& 1(5720)=14823.9 \mathrm{KN}
\end{aligned}
$$

\section{Bearing life}

$\mathrm{L} \square \square_{0}=\frac{L R}{60(N)} *\left(\frac{C 10}{F e}\right)^{3}$

\section{Final calculation for bearing life}

$\mathrm{C} \square=35.1 \mathrm{KN}$

$\mathrm{C}_{0}=19.6 \mathrm{KN}$

$\mathrm{N}$ : Revolution per minute RPM=7000

$\mathrm{Fe}=14824.9 \mathrm{KN}$

$\mathrm{a}=3$ because it is ball bearing

$\mathrm{L} \square \square_{0}=\frac{10^{6}}{60(7000)} *\left(\frac{35100}{14823.9}\right)^{3}=316.07 \mathrm{~h}$

\section{Key Calculation}

The UNS steel shaft is G10350,heat-treated to minimum yield strength has a radius of $25 \mathrm{~mm}$.the shaft rotates at 7000RPm and transmits $143 \mathrm{Nm}$ through a gear. So select an appropriate key for the gear. The key can be seen in the figure 3.1 below.

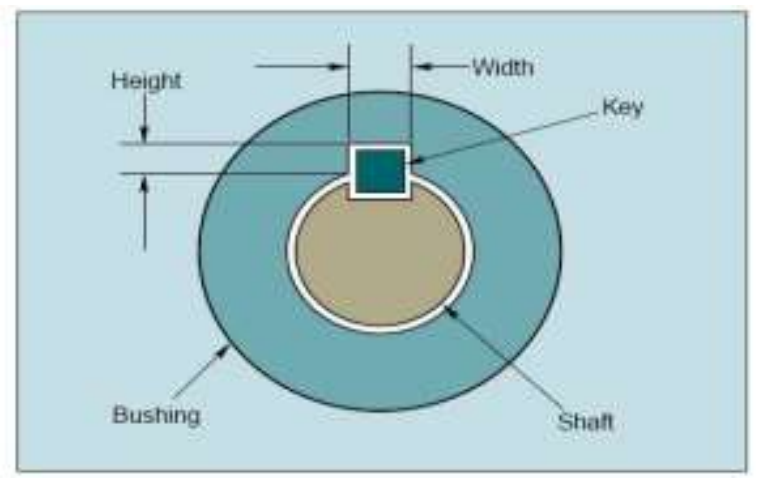

Figure 3.1: $2.024 \mathrm{~mm}$ square key

A 2.024-mm square key is selected, UNS G10200 cold-drawn steel being used .The design will be based on yield strength of $455 \mathrm{MPa}$. A factor of 2.80 will be employed in the absence of exact information about the nature of the load. The torque is obtained from the horsepower equation. 
Vol. 6, No. 7, 2021, PP. 15 - 20

\section{International Journal of Innovations in Engineering and Science, www.ijies.net}

Angle of speed $\mathrm{w}=70000 * 2 / 60=733.04 \mathrm{rad} / \mathrm{s}$

$\mathrm{T}=143 / 733.04=0.195 \mathrm{Nm}$

Force at surface of the shaft is

$\mathrm{F}=\frac{T}{r}=0.195 / 0.025=7.8 \mathrm{~N}$

By the distortion-Energy theory, Ssy will be

Ssy $=0.577 *$ Sy

Ssy $=0.577 * 455=262,535$

Failure by shear a cross and will create a stress of $t=F / L$ substituting the strength divided by the factor of safety for $t$ gives

$$
\text { Ssy/n }=F / t
$$

Which it is $262.535^{*} 10^{\wedge} 6 / 2.80=7.8 / 0.01 \mathrm{~L}$

So $\mathrm{L}=8.31 * 10^{\wedge}-6 \mathrm{~mm}$

To resist crushing, the area of one-half the face of the key is used :

$\mathrm{Sy} / \mathrm{n}=\mathrm{F} / \mathrm{t} 1 / 2$

Which it is $455^{*} 10^{\wedge} 6 / 2.8=7.8 / 0.01 * \mathrm{~L} / 2$

$\mathrm{L}=9.6^{*} 10^{\wedge}-6 \mathrm{~mm}$

The shaft was carefully manufactured after the calculations and hence it can be seen in the figure 3.2 below:

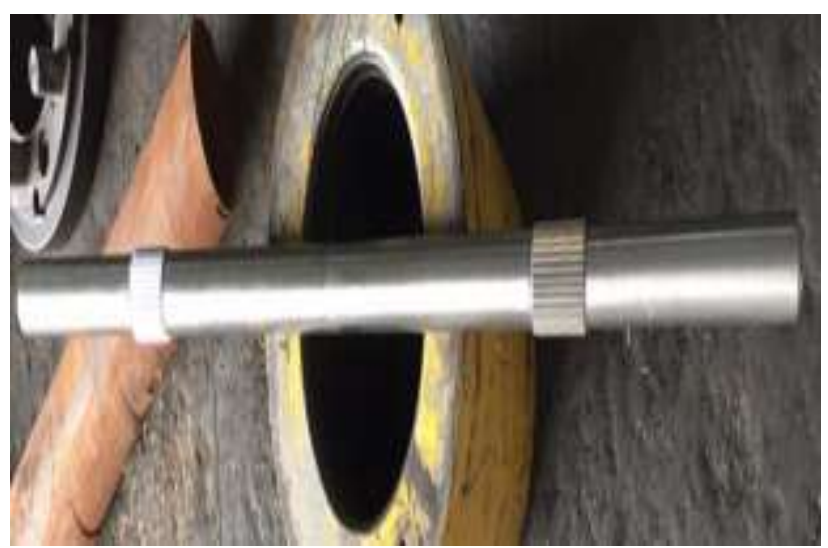

Figure 3.2: Shaft used for our dynamometer

\subsection{Manufacturing and assembly (Implementation)}

The figures 3.5 and 3.6 shows all the parts required to implement our dynamometer project. First, the figure 3.5 shows the caliber stand and the shaft has to be connected to the table which is our base, then discs has to be installed in the shaft where the calibers have to be connected to the stand which is parallel to the shaft. Therefore, figure 3.6 shows the assembled caliber stand and other parts.

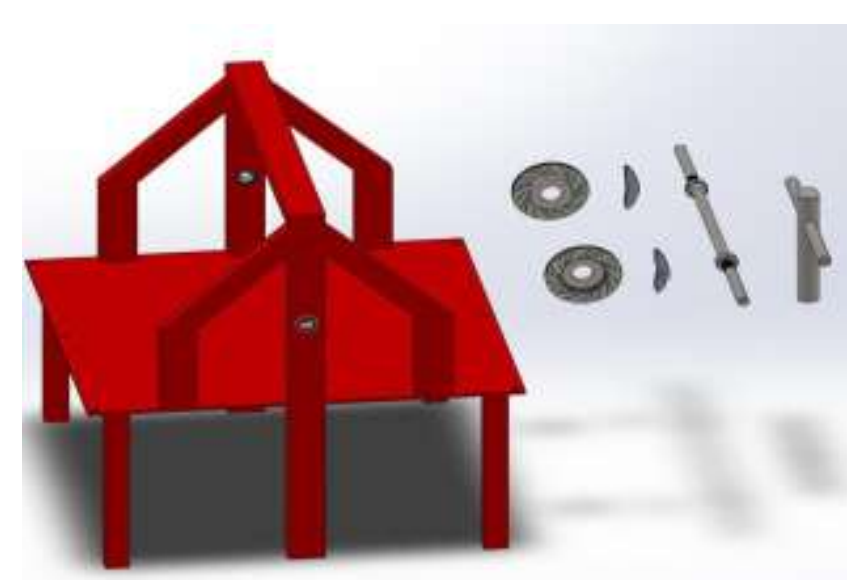

Figure 4.5 Caliber stand with shafts, caliber and other parts

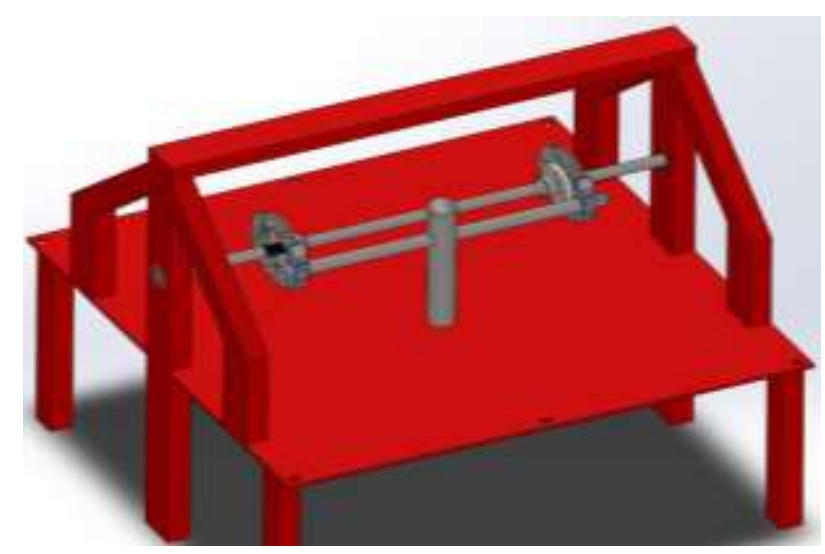

Figure 4.6 (Assembled) Caliber stand with shafts, caliber and other part

\section{System Testing and Analysis}

The setup of the dynamometer can be seen in figure 4.1 below: 


\section{International Journal of Innovations in Engineering and Science, www.ijies.net}

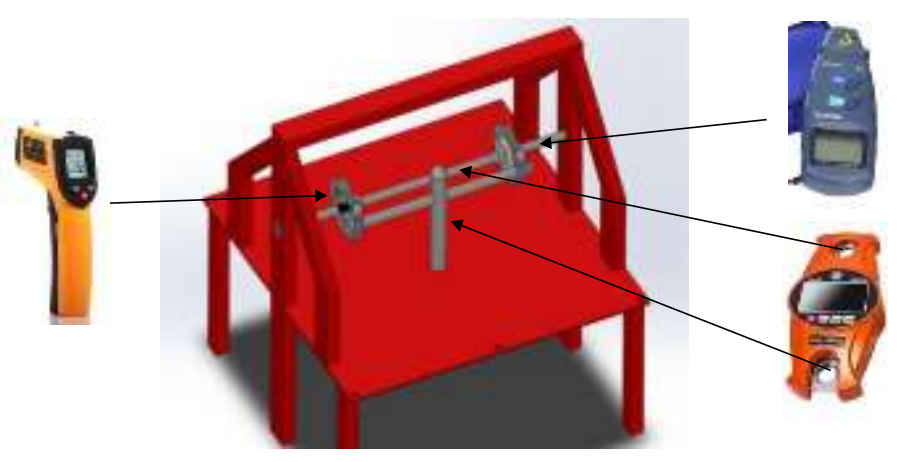

Figure 5.1: Setup \& Location of Sensors

List the specification of the sensor and explain why you chose them.

\section{Force gage specification:}

- Accurate reloading spring sensor

- Large 2" backlight display

- Sturdy built aluminum body

- Digital professional hanging scale up to $300 \mathrm{~kg}$

- Stainless steel rotary hook, shackle

- Mode function $(\mathrm{Ib} / \mathrm{kg} / \mathrm{n})$

- Weight data hold, tare function

- Low battery indication, auto-off

- AAA batteries included

- Net weight 22oz/620g

- Assembled in P.R.C.

\section{Tachometer specifications:}

- Measures the rotational speed with visibale red light beem from a powerful LED

- $\quad$ High intensity class II laser measures from 2.5 - 99,999 RPM

- Extra-large 5-digit LCD display, high accuracy of $+/-0.05 \%$

- Auto zero adjustment, stores last, minimum, and maximum readings

- Can be used for HVAC applications in measuring fan speed

- $\quad$ Powered by 4 x AA battery

- Size: $180 \times 72$ x $37 \mathrm{~mm}(7.0 \times 2.8$ x 1.5 inch.

\section{Thermometer specification:}

- Measurement range: -50 to $650^{\circ} \mathrm{C}$ (-58 to $1202^{\circ} \mathrm{F}$ )

- Accuracy: $\pm 2{ }^{\circ} \mathrm{C}$

- Emissivity: fixed, 0.95

- Field of View: D/S=Approx. 12:1 ratio (D: Distance; $\mathrm{S}=$ Spot or Target)
- Response time: Less than $1 \mathrm{~s}$

- Diode laser: output < $1 \mathrm{mw}$ at 630-670mm class 11 laser produce

- Display: LCD Backlight

- Auto Power Shut Off: YES, 7s

- Low Battery Indication: YES

\section{Reasons of chosen Sensor Devices:}

- Force Gage: it's required for us to measure pulling force through this device

- Tachometer: it's required to measure speed of rotating the shaft RPM

- Thermometer: it's required to measure the changing temperature of disks

- The limited performance of the devices fits our need

- Due to our limited budget we chose smartly to get best quality with low price.

\section{Testing parameters and approach:}

Temperature - Rotation Speed - Pulling Force Efficiency of the System.

Our approach is about observing all changes in parameters from the running time of the system until the braking is applied by the caliper on the disks, which will also lead us to observe the stability of the system and establish high-efficiency production.

\section{V- CONCLUSION}

Working on this senior project was a very rich experience for our future, yet we were faced by many challenges. These challenges included, but not limited to, working under pressure and working effectively as a one team. We had a very limited time to finish the project tasks which some of them requires much time and effort. We were rushed to buy the tools and parts and do the assembling and testing to the machine. At the same moment, we were required to know and understand each other in the team and work effectively to solve the challenges we having. In fact, we overcome these challenges by managing each process of the project alone. The project work was broken down into smaller tasks and these tasks were assigned to individual members of the team or to groups with a certain deadline to finish. This reduces the conflicts and improved the communication among the team. However, management of team and work was not the only challenge, we had more technical and design problems. We used what we learned during our courses to analyze the problems and 


\section{International Journal of Innovations in Engineering and Science, www.ijies.net}

provide the best solution by using critical thinking and best design practices. For example, we used FEA analysis to perform structural and analysis and we used Solid works software to provide the best design solution. We had to be familiar with these advanced tools and techniques in the context of dealing with a real design situations.

During the project time we learnt and improved so many skills and we gained huge amount of knowledge. We learned how to work under pressure and perform complex tasks quickly in short time. We, also, applied what we learned in course to actual work and used the design principles to produce and test a new working machine. These lessons included:

\subsection{Future Scope}

Our future recommendation can summarized briefly in several point :

- Regular checkup and maintenance of the brakes.

- Adding bearing and support in the middle of the shaft is recommended for future work.

- Replacing the motor-shaft coupler to an elastic coupler.

- To better readings in the future, it is recommended to wild the force gage on the frame of the table

- Getting a high efficiency tachometer, will advance future studies.

\section{REFERENCES}

\section{For Mechanical force gauge}

- https://imada.com/product-category/forcemeasurement/force-gauges/mechanicalforce-gauges/

\section{Spring gauge}

- https://en.wikipedia.org/wiki/Spring_scale

- Hewison, Christian H. (1983). Locomotive Boiler Explosions. David and Charles. p. 18. ISBN 0-7153-8305-1.

\section{Deformation gauge (strain gauge)}

[1] https://www.omega.com/prodinfo/straingages.h tml

[2] https://gndec.ac.in/ igs/ldh/conf/2009/articles/T 05_05.pdf
[3]

https://www.google.com.sa/search?q=dynamo meter\&safe=strict\&rlz=1C1PRFB_enS A794SA794\&ei=Rg7eWvPKOcSKgAbSmqjg AQ\&start=10\&sa=N\&biw=1680\&bih= 944.

[4] Earth Policy Institute (EPI), Report 2007, www.epi.org.

[5] International Electrotechnical Commission (IEC) Standard 61724. Photovoltaic system performance monitoring-guidelines for measurement, data exchange and analysis.

[6] T. Oozeki, T. Izawa, K. Otani and K. Kurokawa, "An evaluation method of PV systems," Solar Energy Materials \& Solar cells, vol. 75, 2003, pp. 687-695.

[7] T. Yamaguchi, H. Wakabayashi, T. Yamada, K. Hasegawa, T. Agarashi, K. Sakuta,T. Takashima, and K. Otani, “ Measurement and analysis of residential PV systems in Japanese monitoring program," $3^{\text {rd }}$ World Conference on PV Energy Conversion, Osaka, Japan, May 1118, 2003, pp. 2463-2465.

[8] J. D. Mondol, Y. Yohanis, M. Smyth and B. Norton, "Long term performance analysis of a grid connected photovoltaic system in Northern Ireland," Energy Conversion and Management, vol. 47, 2006, pp. 2925-2947. 